Document downloaded from:

http://hdl.handle.net/10251/165607

This paper must be cited as:

Besharat, M.; Coronado-Hernández, OE.; Fuertes-Miquel, VS.; Viseu, MT.; Ramos, HM. (2019). Computational fluid dynamics for sub-atmospheric pressure analysis in pipe drainage. Journal of Hydraulic Research. 58(4):553-565.

https://doi.org/10.1080/00221686.2019.1625819

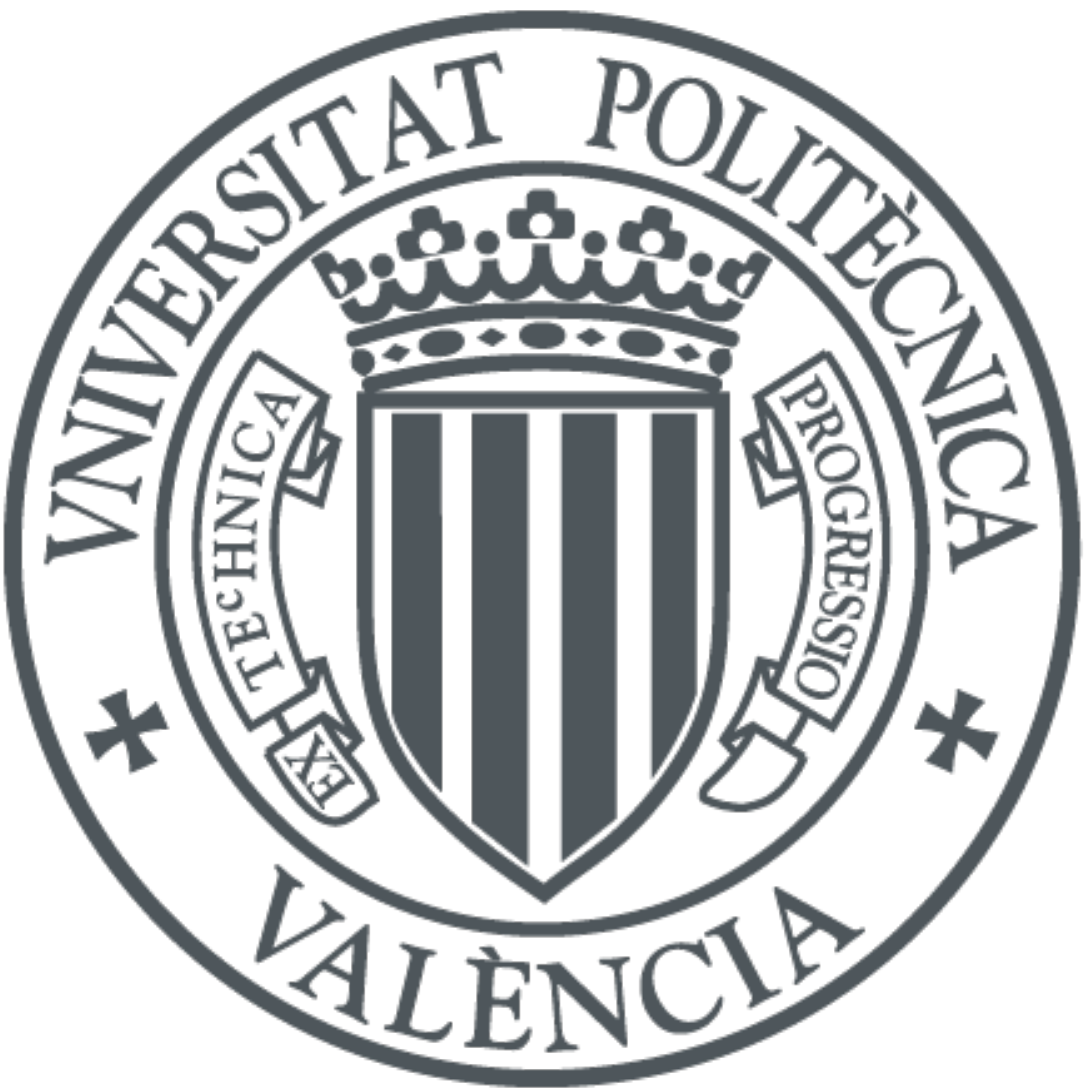

The final publication is available at

https://doi.org/10.1080/00221686.2019.1625819

Copyright Taylor \& Francis

Additional Information 


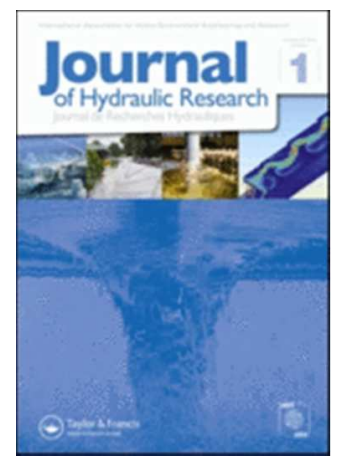

\section{Computational Fluid Dynamics for Sub-Atmospheric Pressure Analysis in Pipe Drainage}

\begin{tabular}{|r|l|}
\hline Journal: & Journal of Hydraulic Research \\
\hline Manuscript ID & TJHR-2018-0082 \\
\hline Danuscript Type: & Research paper \\
\hline Complete List of Authors: & $\begin{array}{l}\text { Besharat, Mohsen; Instituto Superior Técnico (IST), University of Lisbon } \\
\text { (ULisbon), Department of Civil Engineering, Architecture and Georesources } \\
\text { (DECivil); } \\
\text { Coronado-Hernandez, Oscar; Universidad Tecnologica de Bolivar, Facultad } \\
\text { de Ingeniería } \\
\text { Fuertes-Miquel, Vicente; Universitat Politècnica de València, Ingeniería } \\
\text { Hidráulica y Medio Ambiente } \\
\text { Viseu, Maria; Laboratorio Nacional de Engenharia Civil } \\
\text { Ramos, Helena; Instituto Superior Técnico, }\end{array}$ \\
\hline Keywords: & $\begin{array}{l}\text { two-phase flow, CFD simulation, pressure fluctuation, sub-atmospheric } \\
\text { pressure, pipeline drainage }\end{array}$ \\
\hline JHR Keywords: & $\begin{array}{l}\text { Flows in pipes and nozzles < Turbulent flows, High-Reynolds-number } \\
\text { turbulence < Turbulent flows, Turbulence simulation and modeling < } \\
\text { Turbulent flows, Aerated flows and bubble dynamics < Multiphase and } \\
\text { stratified flows, Two- dimensional models < Computational methods in } \\
\text { hydro-environment research and fluid dynamics }\end{array}$ \\
\hline & \\
\hline
\end{tabular}




\section{Computational Fluid Dynamics for Sub-Atmospheric Pressure Analysis in Pipe Drainage}

Mohsen Besharat (IAHR Member), Department of Civil Engineering, Architecture and

Georesources, CERIS, Instituto Superior Técnico, University of Lisbon, Av. Rovisco

Pais, 1, 1049-001, Lisbon, Portugal

Email: mohsen.besharat@tecnico.ulisboa.pt (author for correspondence)

Oscar Enrique Coronado-Hernández, Facultad de Ingeniería, Universidad Tecnológica de Bolívar, Parque Industrial y Tecnológico Carlos Vélez Pombo Km 1 Vía Turbaco, 131001, Cartagena, Colombia; Departamento de Ingenieríia Hidráulica y Medio Ambiente, Universitat Politècnica de València, Camino de Vera S/N CP 46022, Valencia, Spain

Email: ocoronado@unitecnologica.edu.co

Vicente Samuel Fuertes-Miquel (IAHR Member), Departamento de Ingenierí1a Hidráulica y Medio Ambiente, Universitat Politècnica de València, Camino de Vera S/N CP 46022, Valencia, Spain

Email:vfuertes@upv.es

Maria Teresa Viseu, Laboratório Nacional de Engenharia Civil (LNEC), Av. do Brasil, 101, 1700-066, Lisbon, Portugal

Email:tviseu@lnec.pt

Helena Margarida Ramos, Department of Civil Engineering, Architecture and Georesources, CERIS, Instituto Superior Técnico, University of Lisbon, Av. Rovisco Pais, 1, 1049-001, Lisbon, Portugal

Email: helena.ramos@tecnico.ulisboa.pt

Running Head: Sub-atmospheric Pressure Study Using a 2D CFD Model 


\title{
Computational Fluid Dynamics for Sub-Atmospheric Pressure Analysis in Pipe Drainage
}

\begin{abstract}
The sub-atmospheric pressure in gravity pipeline drainage cases can create serious safety issues. To study that, a simple pipeline drainage condition has been studied both experimentally and numerically to evaluate the risky pressure change during this phenomenon. Also, this work aims to demonstrate the ability of computational fluid dynamic models in the simulation of major parameters of similar conditions in design studies. The considered drainage condition includes an air pocket in the highest level of pipeline profile. The emptying process has been examined by a valve opening in the lowest level of the pipeline with no admitted air at the upstream. The results show good accordance with measured data confirming the ability of the proposed model. Additionally, the effect of the air pocket size, the valve opening time and also the valve opening percentage on the pressure graphs have been depicted.
\end{abstract}

Keywords: two-phase flow; CFD simulation; pressure fluctuation; sub-atmospheric pressure; pipeline drainage

\section{Introduction}

Transient flow in piping systems can be analysed using different flow models depending on the type of the behaviour, the complexity of calculation and the adopted boundary conditions. In this sense, two groups of models exist for analysis: $(i)$ the inertial models which consider the water inertia for analysis of the transient condition in the flow direction known as one-dimensional (1D) models (Abreu et al., 1999); (ii) the computational fluid dynamic (CFD) models which can be used either as two-dimensional (2D) or three-dimensional (3D) with more complexity to implement. The most complicated cases in transient flow analysis might be related to trapping an air pocket in the water system or in a lateral protecting device (Zhou, Deyou, Bryan \& Qinfen, 2011a; Besharat, Tarinejad \& Ramos, 2016a; Besharat, Viseu \& Ramos, 2017). As a transient flow condition with entrapped air, the analysis of the filling and emptying processes are very important because they are common problems during operational stages of pipelines (AWWA manual, 2001). The filling process is defined by the compression of an air pocket which produces high peaks of pressures (Izquierdo, Fuertes, Cabrera, Iglesias \& García-Serra, 1999; Zhou \& Liu, 2013; Zhou, Liu \& Karney, 2013a) and a pressure transient (Apollonio et al., 2016) due to the contrast of water and air velocities, a condition that is capable to create a pipe failure situation. Most of the previous case studies of the filling process have presented examples of a simple horizontal pipeline. Zhou et al. (2011a) and Apollonio et al., (2016) presented two studies 
of filling processes in undulating pipeline showing the effect of the size of an air pocket and the downstream conditions. On the other hand, the emptying process is characterized by an expansion of the air pocket producing a sub-atmospheric pressure which can lead to the buckling of the pipe (Coronado-Hernández, Fuertes-Miquel, Besharat \& Ramos, 2017; Fuertes-Miquel, Coronado-Hernández, Iglesias-Rey \& Mora-Melia, 2017). Collins, Boxall, Karney, Brunone and Meniconi (2012) studied the effect of the depressurization on the severe transient pressure in pipelines demonstrating the inherent destructive effect of this phenomenon which must be treated with appropriate caution. The emptying process is potentially capable to cause serious problems when there are no air valves along the pipeline. It represents one of the most critical conditions in the pipeline operation. Hence, the appearance of sub-atmospheric pressure due to the expansion of an air pocket can be explained by the polytropic relation. It imposes that the multiplication of the absolute pressure and the volume of air pocket $\left(p^{*} V_{a}{ }^{k}\right)$ remains constant along the time. So, when the volume of air pocket increases $\left(V_{a}\right)$ the absolute pressure decreases $\left(p^{*}\right)$. The exponent $k$ represents the polytropic coefficient, which can vary from 1.0 (isothermal process) to 1.4 (adiabatic process) (Besharat \& Ramos, 2015).

Recently, the filling and emptying processes have been investigated by several researchers using inertial models with the objectives of: $(i)$ analysing the influence of the air pockets during a filling process (Zhou et al., 2013a; Zhou, Liu \& Karney, 2013b; Besharat, Coronado-Hernández, Fuertes-Miquel, Viseu \& Ramos, 2018), (ii) computing a filling process by neglecting the pipe and water elasticity (Izquierdo et al., 1999), (iii) considering the influence of a bypass pipeline (Wang, Wang, Karney \& Malekpour, 2017), and (iv) computing the drop of sub-atmospheric pressure in a water emptying pipeline (Coronado-Hernández, Fuertes-Miquel, Besharat \& Ramos, 2018). There are serious challenges when dealing with the emptying and filling processes in water pipelines including shifting between free-surface and pressurized flow conditions, the deformation of the interface between two phases and the limitation of models in predicting the air-water interactions (Trindade \& Vasconcelos, 2013). The emptying and filling processes include different behaviours in terms of the dynamic of the flow (Laanearu et al., 2012). The first studies of air intrusion, the bubble motion in liquids due to the gravity and the emptying of pipes were conducted by Zukoski (1966) and Benjamin (1968). In this context, Vasconcelos and Wright (2008) studied flow drainage from an initially filled horizontal pipe by an upstream constant head from a reservoir when the air cavity is intruded from upstream end and a sudden opening occurs at the downstream end. The main objectives of this work were to study the advance of air intrusion and the effect of reservoir head and the criterion of full pipe flows and if it should be based on velocity. Laanearu et al. (2012) studied the emptying process due to pressurized air experimentally in a large-scale pipeline. That study was more focused on experimental achievements. A simple control volume (CV) numerical model was used to predict the measured results. This model showed some deficiencies in the prediction of pressure data 
fluctuations and the length of the air-water tail. Hou et al. (2012) as well presented an experimental study of the filling and emptying processes in the large-scale pipelines. During the case of a filling process, this work mainly studied the lengthening water column and the airwater interface evolution. For the case of an emptying process, authors fulfilled experiments with objectives of studying the hydrodynamics of the shortening water column, the shape and the behaviour of the air-water interface. Results showed that in either case of filling or emptying the water-front does not fill the pipe section completely. Also, the flow regime shows complex change during the phenomenon (Hou et al., 2012). Laanearu, Hou, Annus and Tijsseling (2015a) studied water column mass loss during an emptying process from a horizontal large-scale pipeline by pressurized air when the downstream end was partially closed. This study assessed the change in length of water column using the Zukoski dimensionless number (Zukoski, 1966) and numerical simulations using a CV model. The simulations from the CV model showed differences with the measured data due to the simplifying assumption of the stationary stratified flow behind the water column (Laanearu et al., 2015a). Laanearu, Hou and Tijsseling (2015b) studied experimentally and analytically the air-water interface during the filling and the emptying process using a CV model. Tijsseling, Hou, Bozkus and Laanearu (2016) presented an improved one-dimensional model for the rapid emptying and filling process in pipelines using a variable velocity of the liquid, predicting the right trend and magnitude of flow rate and pressure results better than previous models. However, the trend of flow rates and pressures show a very simple pattern with limited oscillation. Martins (2012) studied the filling process in the vertical and inclined pipes experimentally and numerically with different initial pressures of air pocket showing the fact that the highest pressure peak is related to the atmospheric pressure condition in the air pocket. Since there are few experimental and numerical studies of the emptying process in the literature, this phenomenon is not fully understood and still appropriate numerical models are required. The application of current topic also may go further than water pipelines. In the oil pipelines, the emptying of the oil carries out by injection of a gas (Martinoia, Barreto, da Rocha, Lavoura \& Henriques, 2012) that advances in this topic will also facilitate understanding this phenomenon for other viscosities.

So far, some applications of CFD models have been developed for analyses of the filling processes, column separation and computing the maximum value of pressure surge. Liu and Zhou (2009) studied the condition of rapid filling of a horizontal pipeline with trapped air and dead-end using the volume of fluid (VOF) model in a 2D CFD and compared results with a 1D model. This model showed good ability in predicting the movement of air-water interface. Authors found that based on striking time of the water-front on the pipe end wall and the occurrence time of the first peak, the results from 1D and CFD are different in terms of accuracy (Liu \& Zhou, 2009). Zhou, Liu and Ou (2011b) similarly used the VOF model in a 2D CFD model and also a 3D CFD model to simulate the rapid filling event. In that research, results of 
$2 \mathrm{D}$ and $3 \mathrm{D}$ simulations were compared to the results of $1 \mathrm{D}$ models concluding the superiority of the CFD models over presented 1D model in physical relevance and numerical accuracy. The results of 2D CFD and 3D CFD models were quite consistent. However, authors reported the preference of 2D CFD model due to less computational effort (Zhou et al., 2011b). Martins, Delgado, Ramos and Covas (2017) studied the filling process in a vertical pipe containing trapped air using 3D CFD simulation and VOF model. The model showed good agreement with experimental results. Based on the simulations, two different behaviours of the air-water interface were introduced in terms of a mixture of air and water. Besharat, Tarinejad, Aalami and Ramos (2016b) studied different cases using 2D CFD models including: (i) entrapped air in a vertical pipeline connected to a hydro-pneumatic tank to produce the required pressure, (ii) entrapped air in the middle of a undulating pipeline connected to two hydro-pneumatic tanks to provide the required pressure for compressing the air pocket from both sides and (iii) the water hammer phenomenon in the undulating pipeline with a lateral compressed air vessel to study the compressed air within the air vessel. Authors made a mesh independent analysis to find the best mesh configuration. The proposed 2D CFD model could predict the pressure in the air pocket and the movement of air-water interface.

Nevertheless, the application of the CFD models for simulation of the emptying process still has room for improvement. This research features and investigates a 2D CFD model to simulate the emptying process in a single pipe without admitting air when an air pocket has been trapped in the upper level of the system. The implementation of the CFD model gives relevant information about the behaviour of the main hydraulic and thermodynamic variables, allowing analyses of the behaviour associated with the backflow air. The CFD model was previously validated through the comparison with experimental results, allowing the prediction of suitable experimental results for other hydraulic conditions.

\section{Experimental Model}

A simple pipeline with an internal diameter of $4.2 \mathrm{~cm}$ was configured at the Universitat Politècnica de València in Spain, to conduct experiments for the drainage procedure when an air pocket exists in the upper level of the pipe (Fig. 1). The installation setup is composed of a 4.16 $\mathrm{m}$ long methacrylate transparent pipe, a PVC $90^{\circ}$ elbow, a $0.20 \mathrm{~m}$ PVC pipe length, and a ball valve located at the downstream end. The hydraulic installation is closed at the upstream end where a pressure transducer has been installed at the distance of $0.105 \mathrm{~m}$ from the upper deadend edge to record the data of absolute pressure within an air pocket. By means of changing the air pocket size, the pipe slope, the valve opening percentage and the valve opening time, different types of tests have been accomplished as shown in Table 1 where $x_{o}$ is the length of the air pocket, $\theta$ is the slope of pipe as in Fig. 1 and $V_{m}$ is the valve opening percentage which has 
been considered in the CFD model. Two different slopes of $\theta=26.18^{\circ}$ and $\theta=29.50^{\circ}$ are examined in experimental tests.

As shown in Table 1 and Fig. 1, for each test a completely confined air pocket with a determined size is located in the highest level of the pipeline when the initial pressure is set at the atmospheric pressure. In this study, the experimental results are simulated using a CFD model considering opening times of the valve between 0.10 and $0.50 \mathrm{~s}$.

Each test was done by opening a ball valve located at the lowest point of pipeline and draining the water column after the gravity action. Also, measurements of each test were done two times to increase the accuracy of the measurements.

\section{CFD Model}

Recently, the improvement of computers and the computational methods have urged researchers to use CFD models for numerical calculations. The main motivation for selecting a CFD model can be addressed in the high accuracy of CFD models and the comprehensive information that they provide after a single simulation (Besharat et al., 2016b). The CFD models take advantage of three fundamental physical principles namely the law of mass conservation, Newton's second law and the law of energy conservation (Anderson, 1995). For no-slip velocity condition between fluid phases, the mass conservation and the momentum equations can be written respectively as follow (ANSYS FLUENT R19.0; Wang et al., 2016):

$$
\begin{gathered}
\frac{\partial}{\partial t}\left(\rho_{m}\right)+\nabla\left(\rho_{m} \boldsymbol{v}\right)=0 \\
\frac{\partial}{\partial t}\left(\rho_{m} \boldsymbol{v}\right)+\nabla \cdot\left(\rho_{m} \boldsymbol{v} \boldsymbol{v}\right)=-\nabla p+\nabla \cdot\left[\mu_{m} \cdot\left(\nabla \boldsymbol{v}+\nabla \boldsymbol{v}^{\boldsymbol{T}}\right)\right]+\rho_{m} \boldsymbol{g}+\boldsymbol{F}
\end{gathered}
$$

where $\boldsymbol{v}$ is the fluid velocity, $p$ is the static pressure, $\boldsymbol{g}$ is the gravitational acceleration, $\boldsymbol{F}$ is the body force, $\rho_{m}$ is the mixture density and $\mu_{m}$ is the mixture viscosity. The $\rho_{m}$ and $\mu_{m}$ are functions of the phase volume fraction and density/viscosity of each phase as defined below:

$$
\begin{gathered}
\rho_{m}=\alpha_{a} \rho_{a}+\left(1-\alpha_{a}\right) \rho_{l} \\
\mu_{m}=\alpha_{a} \mu_{a}+\left(1-\alpha_{a}\right) \mu_{l}
\end{gathered}
$$

where the $\alpha_{a}$ is the volume fraction of the air in percentage. For each mesh, if the whole cell is 
occupied by air, the $\alpha_{a}=1$ and if there is no air in the cell $\alpha_{a}=0$. The subscripts $m, a$ and $l$ correspond to the mixture, air, and liquid phases, respectively.

The CFD models are prone to destabilize due to algorithms' limitations (Ding, Visser, Jiang \& Furmanczyk, 2011). The selection of appropriate simulation models, such as a pertinent turbulent model, will increase the efficiency and the accuracy of each simulation. The twoequation $k-\varepsilon$ turbulent model is frequently used in the literature due to good performance, acceptable accuracy and low computational time (Besharat et al., 2016b). This model is also used in current study.

All CFD simulations were carried out in the environment of the ANSYS Fluent R19.0 academic version. The CFD model was built based on information from the experimental data for two different angles shown in Table 1. The geometry of model has been meshed by a combination of unstructured triangular cells in the middle and structured rectangular cells near the walls as shown in Fig. 2. The mesh consists of 60,630 elements with an average face size of $0.003 \mathrm{~m}$. The maximum skewness and aspect ratio were controlled to determine the quality of the cells. The minimum orthogonal quality value was 0.40 when the orthogonal quality for more than $96 \%$ of meshes was higher than 0.79 . The provided mesh configuration was selected based on previous work and mesh independent analysis by Besharat et al. (2016b).

A sliding mesh zone was defined to simulate the action of the valve and it was actuated using a user defined function (UDF) for the different opening percentages and the valve opening times. The valve opening percentage and time were two major parameters during the simulation efforts. So, it was crucial to validate the accuracy of these values for suitable CFD simulations. This was done using the simulation of tests with different behaviours. The determined values were assigned to new simulations.

A transient pressure-based solver was utilized to resolve the coupled equations between pressure, velocity and density, in the compressible flows. The explicit volume of fluid (VOF) multiphase model considering the effect of implicit body forces was taken into account for the discretization, with a realizable $k-\varepsilon$ turbulent model, while using the enhanced wall treatment (EWT) feature for near-wall calculations. Two different phases namely air and water were constructed in the simulations. An ideal gas condition was defined for the air phase. The drainage action is done only from one end at the lowest position of the model as shown in Fig. 1. All other edges of the model are completely confined and were considered as the pipe wall during the simulations. A pressure outlet boundary condition is assigned to the drainage position namely the downstream dead-end. The values of the absolute pressures at the outlet edge were considered as $1 \mathrm{~atm}$. An interface has been defined in the link between the main body and the valve in order to enable the flow transition. The CFD model uses the pressure implicit with the splitting of operators (PISO) method for coupling the pressure-velocity formulations. The spatial discretization was carried out using a finite volume approach. The pressure staggering option 
(PRESTO) discretization scheme is used for the pressure, while for other spatial discretization a second order upwind scheme is adopted. For the interface tracking method, the compressive scheme was implemented which is a second-order reconstruction scheme based on a slope limiter parameter (ANSYS FLUENT R19.0). The time step was set to $0.001 \mathrm{~s}$ for simulations of this research. The simulation was carried out on a desktop computer: Intel(R) Core(TM) i74790K CPU@4.00GHz, 4 Core(s), 8 Logical Processor(s) with an installed physical memory of 16 GB.

\section{Results and Discussion}

The pressure variations during the emptying process demonstrate the effect of the air pocket on the sub-atmospheric pressure occurrence showing low sub-atmospheric pressures in studied cases. For opening percentages of $10 \%$ and $12 \%$ with every air pocket size, the pressure decreases very fast followed by a rapid dissipation and minor fluctuations as demonstrated in Figure 3 including the tests 1, 2, 3, 7, 8 and 9. The minimum sub-atmospheric pressure head for these two tests shows a value around $8 \mathrm{~m}$ which addresses a gauge pressure head around $-2 \mathrm{~m}$. For the opening percentages of $6 \%$, the pressure decreases rapidly but the fluctuation of the pressure is very limited as in Figure 4. This behaviour corresponds to tests 4, 5, 6, 10, 11 and 12. The minimum pressure head for this case is higher than the previous one by an absolute pressure of $8.50 \mathrm{~m}$ or gauge pressure around $-1.50 \mathrm{~m}$. For both cases, the proposed CFD model is able to calculate the pressure results from experimental tests accurately.

Deformation of the air pocket size occurs very uniformly and the air pocket size increases gradually during the emptying process. Change in opening percentage will not affect the pattern of deformation of the air pocket, even for the smallest opening percentage of the valve. As shown in Fig. 5, the air pocket size continuously increases during the emptying process for test 1 despite the backflow air occurrence. The backflow air enters the pipeline at the atmospheric pressure $(101,325 \mathrm{~Pa})$ at time $1.00 \mathrm{~s}$, but only a limited volume of the air intrudes due to the low opening percentage $\left(V_{m}\right)$ of the valve. The air-water interface continuously changes along the time with a parallel tendency to the static condition. It takes $0.10 \mathrm{~s}$ for $12 \%$ opening of the valve in test 1 . The CFD simulations show that the development of the backflow air acts a substantial role in the adjustment of the drop of sub-atmospheric pressure. The higher backflow admittance leads to a higher sub-atmospheric pressure which is safer for the pipeline. From this explanation, the trend of pressure graphs can be understood in more details. Before happening the backflow air ay time $1.00 \mathrm{~s}$ for test 1 , the pressure increases from the time $0.38 \mathrm{~s}$ to $0.68 \mathrm{~s}$ and again decreases until the time $0.98 \mathrm{~s}$ (Figs. 3 and 5). Figure 5 shows that the fluctuations of the air-water interface at times 2.00, 2.50 and 3.00 are quite limited. The fast dissipation after time $1.00 \mathrm{~s}$ in test 1 can be stated as a result of increasing the air pocket mass by 
joining air bubbles caused by backflow air occurrence. This trend will be continued until all the pipe is filled with air, as well as for all other measured and simulated conditions shown in Table 1 the behaviour is the same.

Figure 6 presents the velocity vectors for different times during the emptying process for test 1 . Vectors show the formation of a flow separation zone due to the flow vein contraction induced by the small aperture of the valve at the time $0.10 \mathrm{~s}$. Then the velocity distributes towards the upstream direction showing the backflow air movement (until $\mathrm{t}=3.00 \mathrm{~s}$ ). The provided legends demonstrate the velocity magnitude showing the highest value about $1 \mathrm{~m} / \mathrm{s}$ at time $0.10 \mathrm{~s}$ when no backflow air still exists. Before entering the backflow air, the flow regime shows no vortex and eddy. After entering the backflow air in time $1.00 \mathrm{~s}$, some eddy flows appear affecting the flow velocity and decreasing it. By developing the backflow air, eddies influence upstream flow. After this time, the regime gains a stable pattern. The interaction of air and water takes place in the middle of the pipe with eddy flow condition. This behaviour is the same in all simulated cases.

Figure 7 presents the velocity contours for test 1 for different times during the emptying process. The stable aforementioned emptying pattern can be proved by observing the velocity contours in Fig. 7. The development of backflow air is detectable in time $1.00 \mathrm{~s}$ and the pattern has been completed by time $2.50 \mathrm{~s}$ when the middle longitude pipe section of the flow has less flow velocity due to eddies representing the backflow in the left side and the emptying flow in the right side. The mean velocity is a value around $0.10 \mathrm{~m} / \mathrm{s}$ during all tests. This small magnitude of the mean velocity results from the small opening percentage of the valve $\left(V_{m}\right)$, the effect of the developed eddies and the length of the water column.

By means of the CFD simulation, a wide range of information about the expansion of the air, the backflow entrance, and emptying flow pattern has been obtained which can be important during the design phase of a pipeline. This study shows that occurring drainage event in a gravity pipeline even with a small opening percentage of the valve is able to create significant sub-atmospheric pressure. Similar surge events should be accurately modelled and analysed to find likely associated risks. The CFD simulations give information about the effect of valve opening time and percentage as shown in Fig. 8. The faster the valve opens, the sooner sub-atmospheric pressure occurs as presented in Fig. 8.

Also, increasing the valve opening percentage and as well as decreasing the air pocket size will cause lower sub-atmospheric pressure (Fig. 9). But in general, the combination of the valve opening percentage and air pocket size mostly identifies the trend of the pressure variation when the opening percentage is more dominant. It means bigger valve opening percentage with the same air pocket size leads to lower sub-atmospheric pressure as it is evident in Fig. 9. This fact appears due to the higher kinetic energy of the gravity force in the exit flow when the valve is more opened. 


\section{Conclusions}

Experimental and numerical studies of a pipeline drainage process under gravity force having a confined air pocket at the highest level are developed and 2D CFD analyses were carried out for simulation and comparison with experimental results. The CFD model provides a wide range of information from whole parts of the pipe system with an acceptable computing time. The pressure and velocity values can be estimated by the CFD model with high accuracy. The depicted velocity vectors unveil eddies in the flow, describe the main reasons for pressure variations and characterize the emptying patterns.

Using appropriate interface tracking method allows identifying the behaviour of an air pocket in terms of expansion behaviour, pressure and velocity propagation. A mixed two-phase flow during the drainage process is identified through the CFD simulation. The CFD model predicts the backflow air movement and the interface transition. The calculation of the air-water interface reveals the backflow air pattern which includes three zones, i.e., $(i)$ a backflow zone in the upper layer of flow, (ii) a mix eddy zone in the middle layer of flow, and (iii) a drainage flow in the lower layer of flow.

The relationship between major parameters of the system such as the pressure, the backflow air and the flow velocity can be understood. It highlights the understanding towards the prediction of the trend of pressure variation, the sub-atmospheric pressure occurrence time and value and the flow regime in a real system. Main reasons behind occurrences of the special pattern can be revealed for the drop of sub-atmospheric pressure.

This CFD model can be used in the final design phase providing useful information about the behaviour of air during the pipe drainage, such as the change in air size, the shape of air-water interface, the amount of backflow air entering into the pipe system and finally the flow pattern during the emptying. To avoid the big computational costs related usually to CFD simulations, a localized section of the pipeline can be modelled when the effect of other parts is included by specific boundary conditions as presented. This can decrease the computational efforts to an acceptable range and prevent potentially harmful events induced by drainage procedure.

Finally, the valve operation effect on the response of a pipe system can be predicted. CFD simulations might be used to set an efficient opening plan of forcing the system to follow the design limitations as well as in the definition of design rules. In the current research, two rules for the valve operation were stated: decreasing the valve opening time causes the pressure changes occur faster and increasing the valve opening percentage leads to lower sub-atmospheric pressures. 


\section{Funding}

The authors acknowledge the financial support for Oscar E. Coronado-Hernández, doctoral student, covered by Fundación CEIBA - Gobernación de Bolívar (Colombia) and Mohsen Besharat covered by Fundação para a Ciência e a Tecnologia (FCT), Portugal.

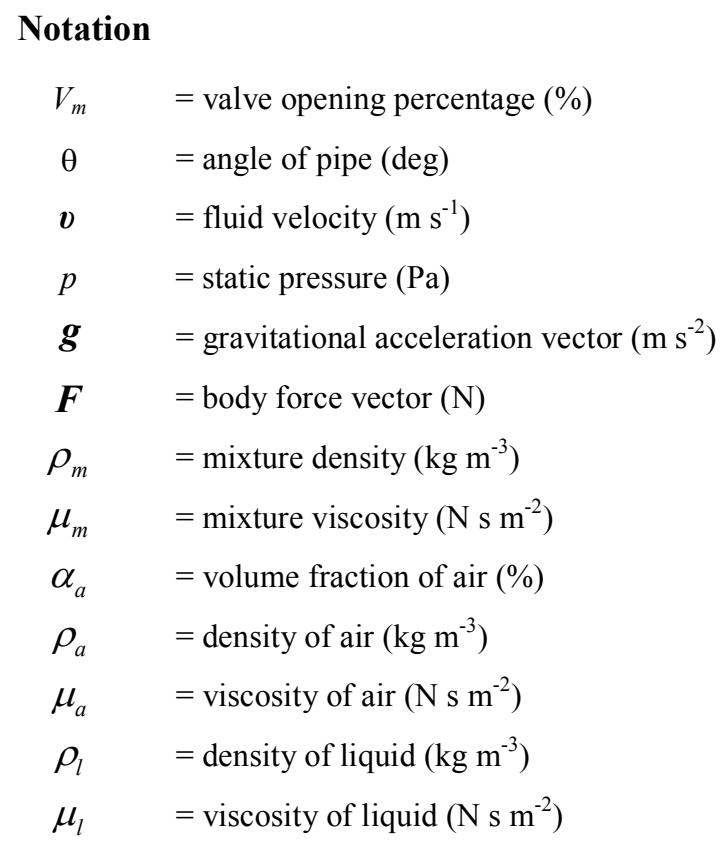

\section{References}

Abreu, J., Cabrera, E., Izquierdo, J., \& García-Serra, J. (1999). Flow Modeling in Pressurized Systems Revisited. Journal of Hydraulic Engineering, 125, 1154-1169.

American Water Works Association (AWWA). (2001). Manual of water supply practices M51: Air-release, air-vacuum, and combination air valves. Denver, CO, USA.

Apollonio, C., Balacco, G., Fontana, N., Giugni, M., Marini, G., \& Piccinni, A. F. (2016). Hydraulic Transients Caused by Air Expulsion during Rapid Filling of Undulating Pipelines. Water, 8, 25.

Anderson, J. D. (1995). Computational fluid dynamics. NY: McGraw-Hill Book Co. ANSYS FLUENT R19.0 academic [Computer software]. ANSYS, Canonsburg, PA. 
Benjamin, T. B. (1968). Gravity Currents and Related Phenomena. Journal of Fluid Mechanics, 31(2), 209-248.

Besharat, M., \& Ramos, H. M. (2015). Theorical and experimental analysis of pressure surge in a two-phase compressed air vessel. 12th International Conference on Pressure Surges, BHR Group, Ireland, Dublin, 729-744.

Besharat, M., Tarinejad, R., \& Ramos, H. M. (2016a). The effect of water hammer on a confined air pocket towards flow energy storage system. Journal of Water Supply Resources Technology-AQUA, 65, 116-126.

Besharat, M., Tarinejad, R., Aalami, M. T., \& Ramos, H. M. (2016b). Study of a Compressed Air Vessel for Controlling the Pressure Surge in Water Networks: CFD and Experimental Analysis. Water Resources Management, 30(8), 2687-2702.

Besharat, M., Viseu, M. T., \& Ramos, H. M. (2017). Experimental study of air vessel sizing to either store energy or protect the system in the water hammer occurrence. Water, 9(1), 63.

Besharat, M, Coronado-Hernández, O. E., Fuertes-Miquel, V. S., Viseu, M. T., \& Ramos, H. M. (2018). Backflow Air and Pressure Analysis in Emptying Pipeline Containing Entrapped Air Pocket. Urban Water Journal, Manuscript submitted for publication.

Collins, R. P., Boxall, J. B., Karney, B. W., Brunone, B., \& Meniconi, S. (2012). How Severe can Transients be after a Sudden Depressurization? Journal of American Water Works Association, 104(4), E243-E251.

Coronado-Hernández, O. E., Fuertes-Miquel, V. S., Besharat, M., \& Ramos, H. M. (2017). Experimental and Numerical Analysis of a Water Emptying Pipeline Using Different Air Valves. Water, 9(2), 1-15.

Coronado-Hernández, O. E., Fuertes-Miquel, V. S., Besharat, M., \& Ramos, H. M. (2018). Subatmospheric pressure in a water draining pipeline with an air pocket. Urban Water Journal (in press).

Ding, H., Visser, F. C., Jiang, Y., \& Furmanczyk, M. (2011). Demonstration and Validation of a 3D CFD Simulation Tool Predicting Pump Performance and Cavitation for Industrial Applications. Journal of Fluids Engineering, ASME, 133(1): 011101.

Fuertes-Miquel, V. S., Coronado-Hernández, O. E., Iglesias-Rey, P. L., \& Mora-Melia, D. (2017). Transient Phenomena during the Emptying Process of a Single Pipe with WaterAir Interaction. Journal of Hydraulic Research (in press).

Hou, Q., Tijsseling, A. S., Laanearu, J., Annus, I., Koppel, T., Bergant, A., ... Rup-recht, A. (2012). Experimental Study of Filling and Emptying of a Large-scale Pipeline. External Report, CASA Report No. 12-15, Technische Universiteit Eindhoven.

Izquierdo, J., Fuertes, V. S., Cabrera, E., Iglesias, P., \& García-Serra, J. (1999). Pipeline StartUp with Entrapped Air. Journal of Hydraulic Research, 37, 579-590. 
Laanearu, J., Annus, I., Koppel, T., Bergant, A., Vučkovič, S., Hou, Q., ... van’t Westende, J. M. C. (2012). Emptying of Large-Scale Pipeline by Pressurized Air. Journal of Hydraulic Engineering, 138(12), 1090-1100.

Laanearu, J., Hou, Q., Annus, A., \& Tijsseling, A. S. (2015a). Water-Column Mass Losses During Emptying of a Large-Scale Pipeline by Pressurized Air. Proceedings of the Estonian Academy of Sciences, 64(1), 8-16.

Laanearu, J., Hou, D. Q., \& Tijsseling, A. S. (2015b). Experimental and Analytical Study of the Air-Water Interface Kinematics during Filling and Emptying of a Horizontal Pipeline. 12th International Conference on Pressure Surges, BHR Group, Ireland, Dublin, 625 637.

Liu, D. Y., \& Zhou, L. (2009). Numerical Simulation of Transient Flow in Pressurized Water Pipeline with Trapped Air Mass. Asia-Pacific Power and Energy Engineering Conference, IEEE Power and Energy Society, New York, 104-107.

Martinoia, T., Barreto, C. V., da Rocha, J. C. D. C., Lavoura, J., \& Henriques, F. M. P. (2012). Simulation and Planning of Pipeline Emptying Operations. Proceeding of the 9th Int. Pipeline Conference, ASME, IPC2012-90432, 603-611.

Martins, S. C. (2012). Pressurization Dynamics of Hydraulic Systems with Entrapped Air. (Unpublished Doctoral Dissertation), Instituto Superior Técnico, Universidade de Lisboa (in Portuguese).

Martins, N. M. C., Delgado, J. N., Ramos, H. M., \& Covas, D. I. C. (2017). Maximum Transient Pressures in a Rapidly Filling Pipeline with Entrapped Air Using a CFD Model. Journal of Hydraulic Research, 1-14.

Tijsseling, A., Hou, Q., Bozkus, Z., \& Laanearu, J. (2016). Improved One-Dimensional Models for Rapid Emptying and Filling of Pipelines. Journal of Pressure Vessel Technology, 138, 031301.

Trindade, B. C., \& Vasconcelos, J. G. (2013). Modeling of Water Pipeline Filling Events Accounting for Air Phase Interactions. Journal of Hydraulic Engineering, 139 (9).

Vasconcelos, J. G., \& Wright, S. J. (2008). Rapid Flow Startup in Filled Horizontal Pipelines. Journal of Hydraulic Engineering, 134, 984-992.

Wang, H., Zhou, L., Liu, D., Karney, B., Wang, P., Xia, L. ... Xu, C. (2016). CFD Approach for Column Separation in Water Pipelines. Journal of Hydraulic Engineering, 142(10).

Wang, L., Wang, F., Karney, B., \& Malekpour, A. (2017). Numerical Investigation of Rapid Filling in Bypass Pipelines. Journal of Hydraulic Research, 0, 1-10.

Zhou, L., Deyou, L., Bryan, K., \& Qinfen, Z. (2011a). Influence of Entrapped Air Pockets on Hydraulic Transients in Water Pipelines. Journal of Hydraulic Engineering, 137, 16861692. 
Zhou, L., Liu, D., \& Ou, C. (2011b). Simulation of flow transients in a water filling pipe containing entrapped air pocket with VOF model. Engineering Applications of Computational Fluid Mechanics, 5, 127-140.

Zhou, L., \& Liu, D. (2013). Experimental Investigation of Entrapped Air Pocket in a Partially Full Water Pipe. Journal of Hydraulic Research, 51, 469-474.

Zhou, L., Liu, D., \& Karney, B. (2013a). Phenomenon of White Mist in Pipelines Rapidly Filling with Water with Entrapped Air Pocket. Journal of Hydraulic Engineering, 139, 1041-1051.

Zhou, L., Liu, D., \& Karney, B. (2013b). Investigation of Hydraulic Transients of Two Entrapped Air Pockets in a Water Pipeline. Journal of Hydraulic Engineering, 139, 949-959.

Zukoski, E. E. (1966). Influence of Viscosity, Surface Tension, and Inclination Angle on Motion of Long Bubbles in Closed Tubes. Journal of Fluid Mechanics, 25(4), 821-837. 
1

2

3

4

5

6

7

8

9

10

11

12

13

14

15

16

17

18

19

20

21

22

23

24

25

26

27

28

29

30

31

32

33

34

35

36

37

38

39

40

41

42

43

44

45

46

47

48

49

50

51

52

53

54

55

56

57

58

59

60

\section{List of tables}

Table 1 Specifications of experimental tests 


\section{List of figures}

Figure 1 Experimental facility of a single sloped pipe for analyzing the drainage procedure at the Universitat Politècnica de València, Spain

Figure 2 The generated mesh in the pipe system near the drainage valve; (a) fully closed, (b) $10 \%$ opened

Figure 3 Pressure variation during tests 1 (left) and 7 (right)

Figure 4 Pressure variation during tests 6 (left) and 12 (right)

Figure 5 The volume fraction contour showing the behaviour of the air expansion and backflow during test 1 (any colour other than the described ones shows a mixture phase)

Figure 6 Velocity vectors during the drainage of test 1

Figure 7 Velocity contour during the drainage of test 1

Figure 8 Comparison of valve opening time (left) and valve opening percentage (right) on the pressure shift for test 1

Figure 9 Pressure variation from experimental data for all accomplished tests 
Table 1 Specifications of experimental tests

\begin{tabular}{ccccccccccccc}
\hline Test No. & 1 & 2 & 3 & 4 & 5 & 6 & 7 & 8 & 9 & 10 & 11 & 12 \\
\hline$x_{o}(\mathrm{~m})$ & 0.205 & 0.340 & 0.450 & 0.205 & 0.340 & 0.450 & 0.205 & 0.340 & 0.450 & 0.205 & 0.340 & 0.450 \\
$\theta$ (deg.) & 26.18 & 26.18 & 26.18 & 26.18 & 26.18 & 26.18 & 29.50 & 29.50 & 29.50 & 29.50 & 29.50 & 29.50 \\
$V_{m}(\%)$ & 12 & 12 & 12 & 6 & 6 & 6 & 10 & 10 & 10 & 6 & 6 & 6 \\
\hline
\end{tabular}




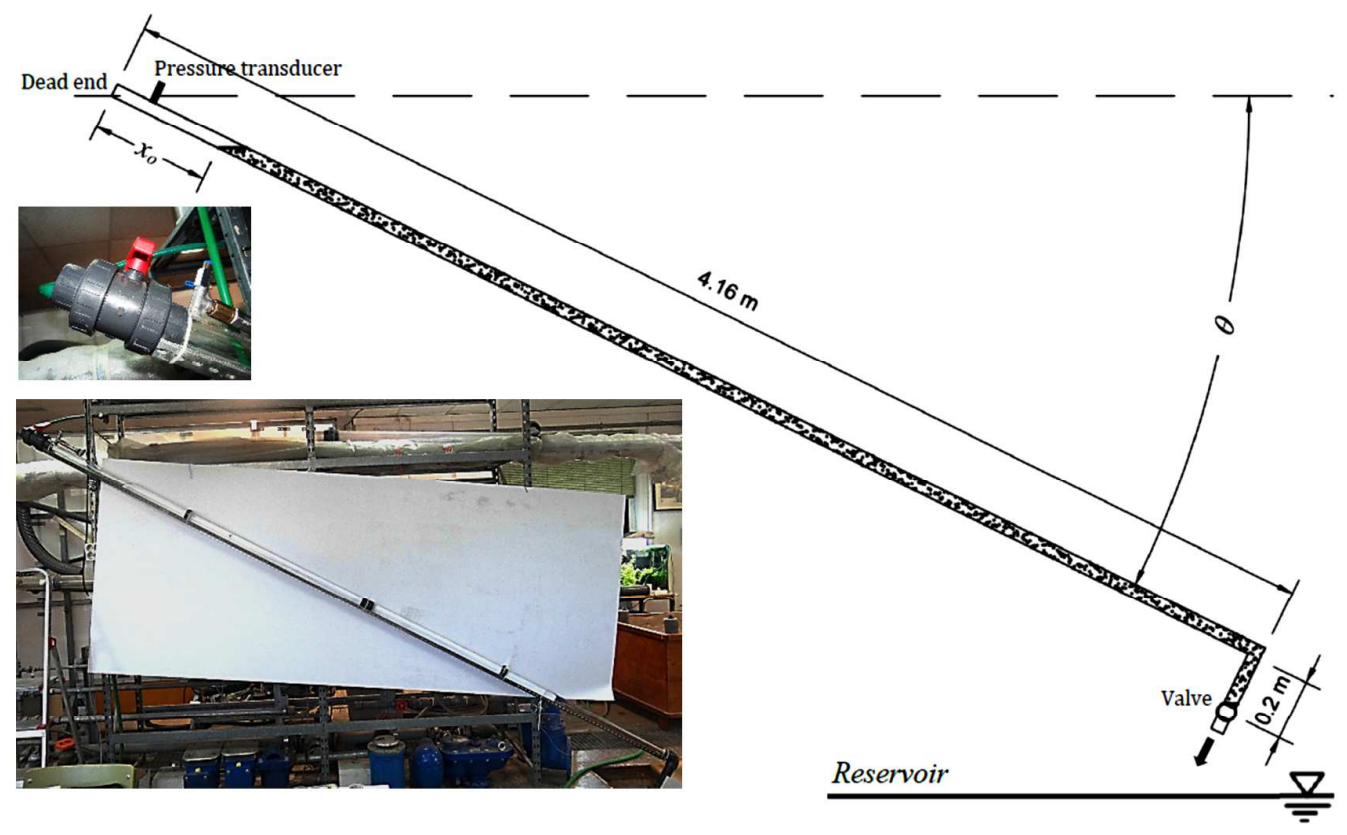

Figure 1 Experimental facility of a single sloped pipe for analyzing the drainage procedure at the Universitat Politècnica de València, Spain 

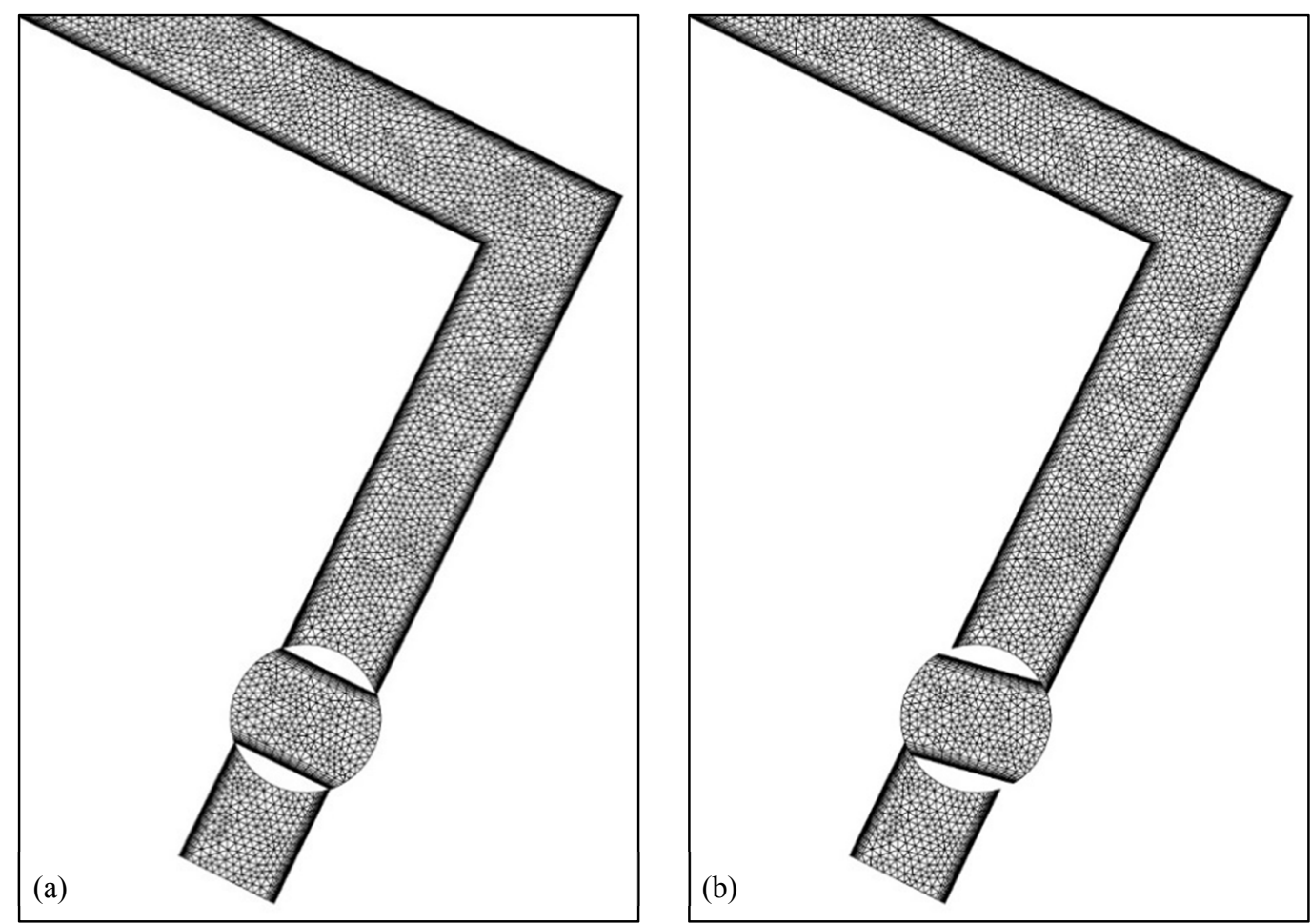

Figure 2 The generated mesh in the pipe system near the drainage valve; (a) fully closed, (b) $10 \%$ opened 

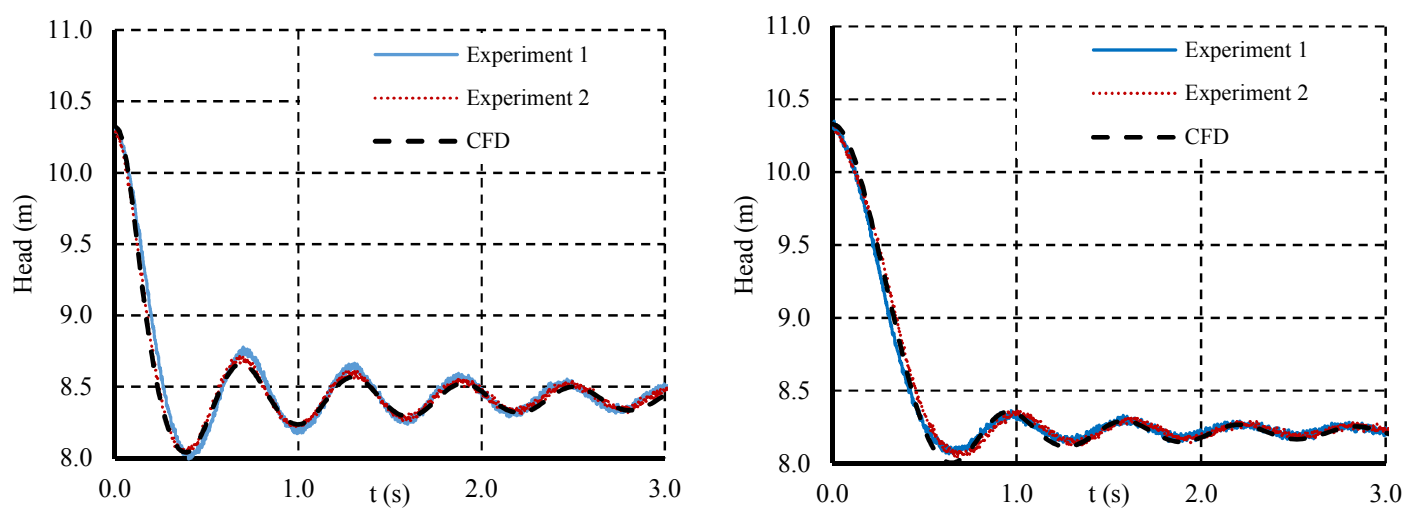

Figure 3 Pressure variation during tests 1 (left) and 7 (right) 

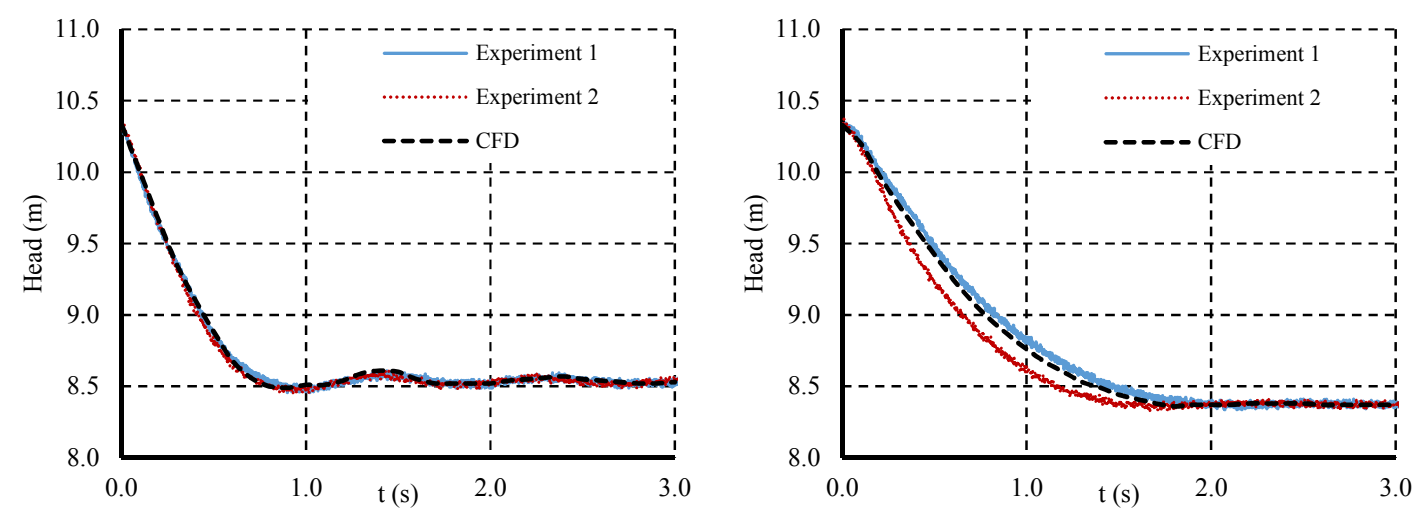

Figure 4 Pressure variation during tests 6 (left) and 12 (right) 

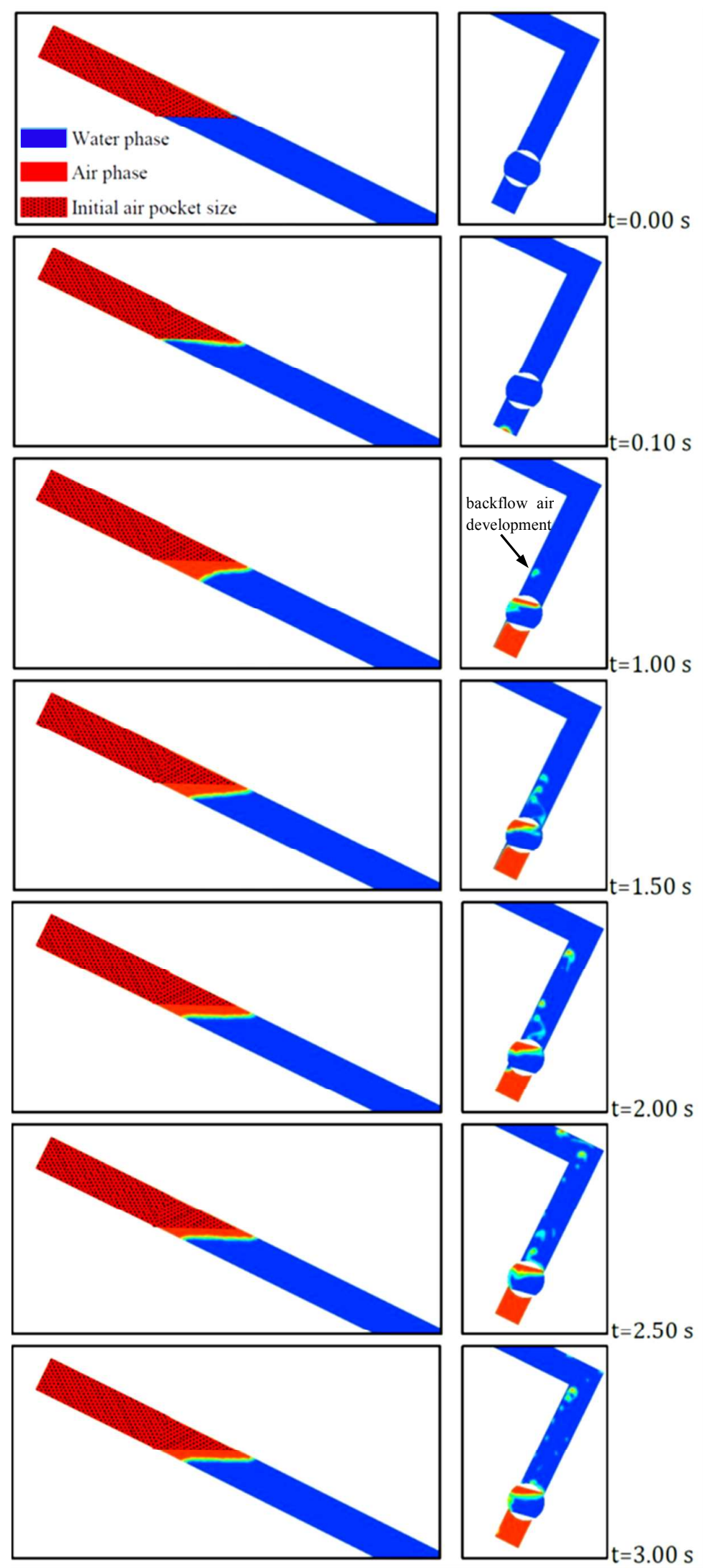

Figure 5 The volume fraction contour showing the behavior of the air expansion and backflow during test 1 (any color other than the described ones shows a mixture phase) 

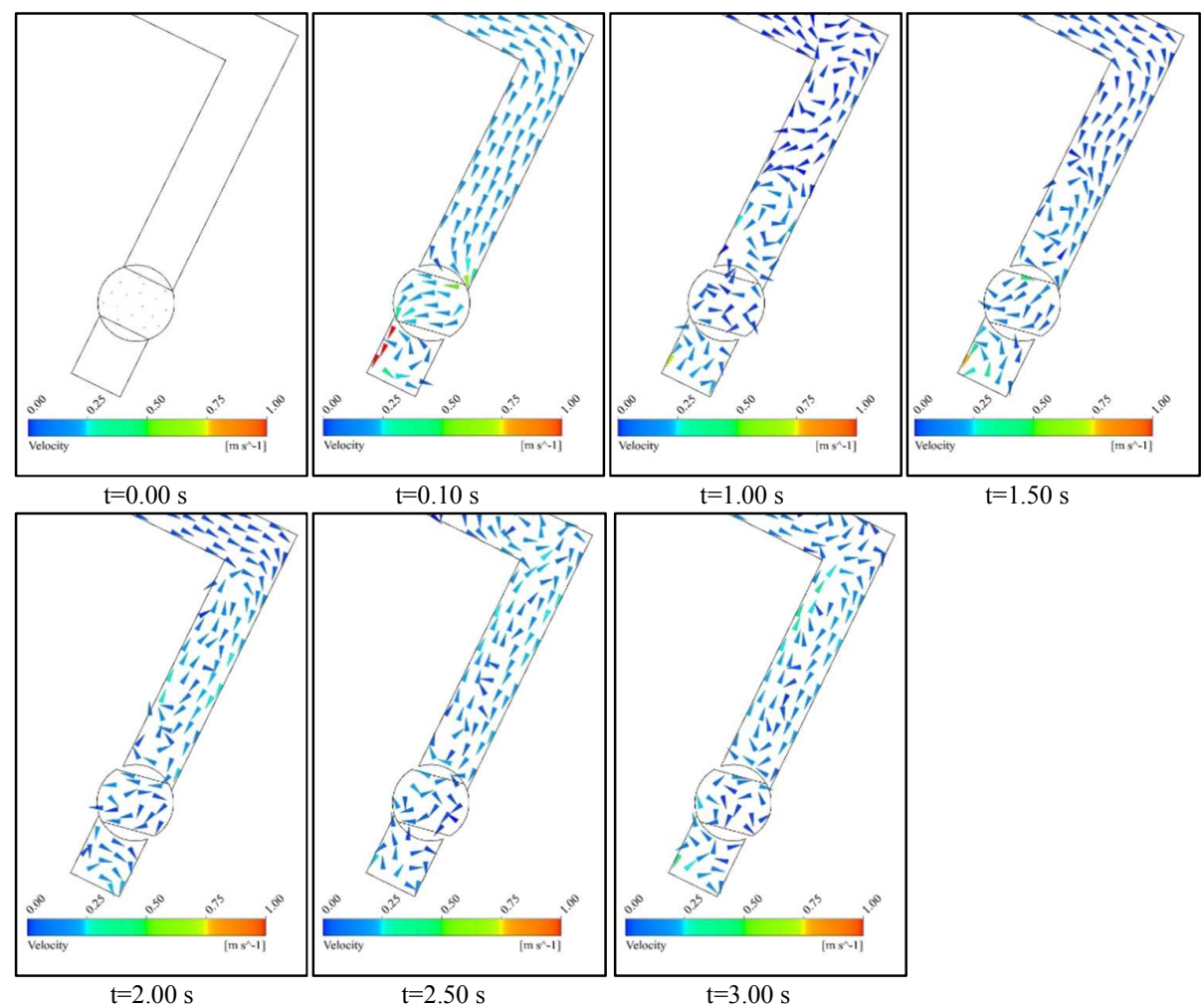

Figure 6 Velocity vectors during the drainage of test 1 

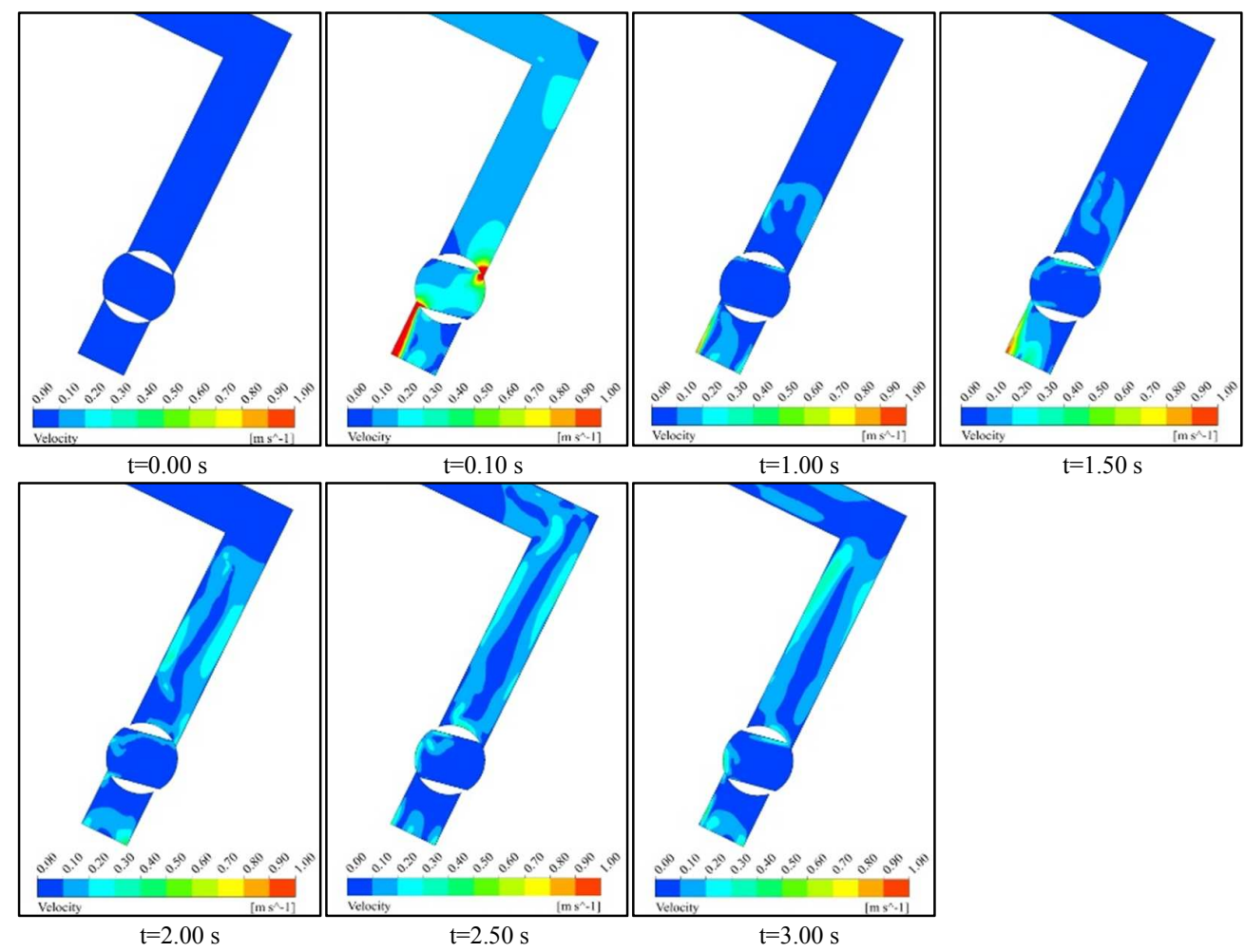

Figure 7 Velocity contour during the drainage of test 1 

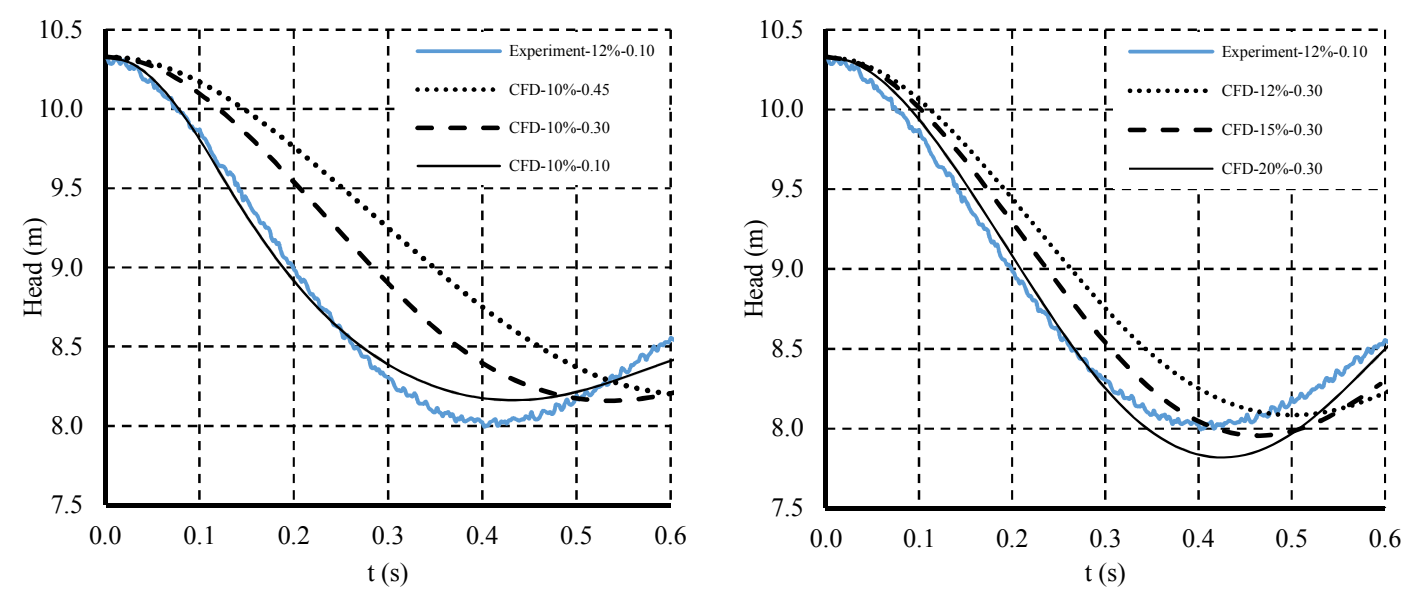

Figure 8 Comparison of valve opening time (left) and valve opening percentage (right) on the pressure shift for test 1 

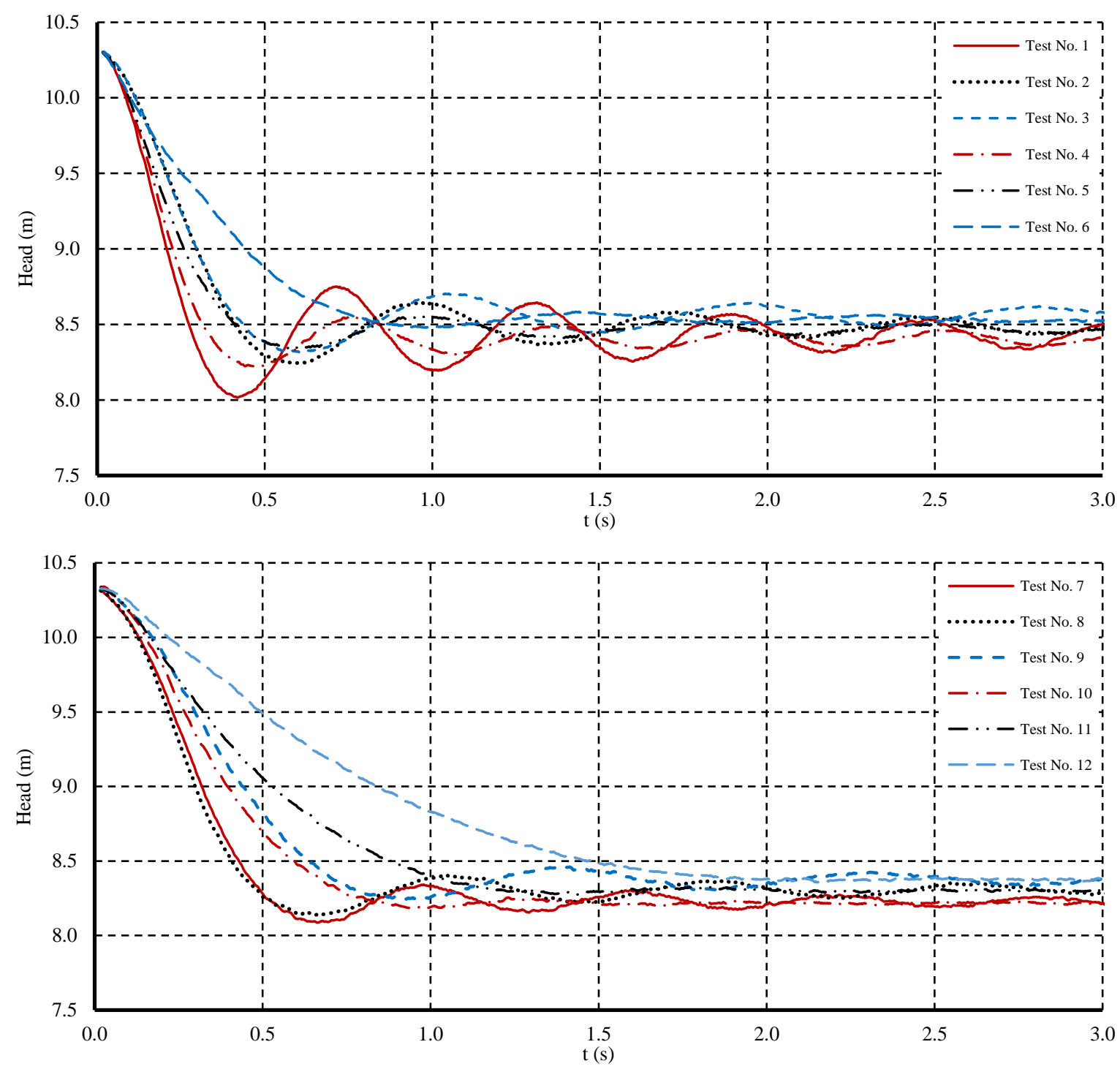

Figure 9 Pressure variation from experimental data for all accomplished tests 